\title{
Hydrogen Treatment and FeOOH overlayer: Effective approaches for enhancing the photoelectrochemical water oxidation performance of bismuth vanadate thin films
}

Singh, Aadesh P. ; Saini, Nishant ; Mehta, Bodh R. ; Hellman, Anders; landolo, Beniamino; Wickman, Björn

Published in:

Catalysis Today

Link to article, DOI:

10.1016/j.cattod.2018.03.041

Publication date:

2019

Document Version

Peer reviewed version

Link back to DTU Orbit

Citation (APA):

Singh, A. P., Saini, N., Mehta, B. R., Hellman, A., landolo, B., \& Wickman, B. (2019). Hydrogen Treatment and FeOOH overlayer: Effective approaches for enhancing the photoelectrochemical water oxidation performance of bismuth vanadate thin films. Catalysis Today, 321-322, 87-93. https://doi.org/10.1016/j.cattod.2018.03.041

\section{General rights}

Copyright and moral rights for the publications made accessible in the public portal are retained by the authors and/or other copyright owners and it is a condition of accessing publications that users recognise and abide by the legal requirements associated with these rights.

- Users may download and print one copy of any publication from the public portal for the purpose of private study or research.

- You may not further distribute the material or use it for any profit-making activity or commercial gain

- You may freely distribute the URL identifying the publication in the public portal 


\section{Accepted Manuscript}

Title: Hydrogen Treatment and FeOOH overlayer: Effective approaches for enhancing the photoelectrochemical water oxidation performance of bismuth vanadate thin films

Authors: Aadesh P. Singh, Nishant Saini, Bodh R. Mehta, Anders Hellman, Beniamino Iandolo, Björn Wickman

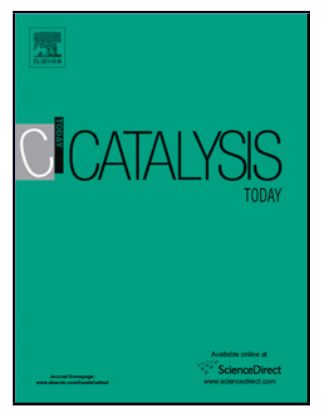

PII:

DOI:

Reference: $\quad$ CATTOD 11324

S0920-5861(18)30291-8

To appear in: $\quad$ Catalysis Today

Received date: $\quad$ 4-7-2017

Revised date: $\quad$ 13-3-2018

Accepted date: $\quad$ 22-3-2018

Please cite this article as: Singh AP, Saini N, Mehta BR, Hellman A, Iandolo B, Wickman $\mathrm{B}$, Hydrogen Treatment and $\mathrm{FeOOH}$ overlayer: Effective approaches for enhancing the photoelectrochemical water oxidation performance of bismuth vanadate thin films, Catalysis Today (2010), https://doi.org/10.1016/j.cattod.2018.03.041

This is a PDF file of an unedited manuscript that has been accepted for publication. As a service to our customers we are providing this early version of the manuscript. The manuscript will undergo copyediting, typesetting, and review of the resulting proof before it is published in its final form. Please note that during the production process errors may be discovered which could affect the content, and all legal disclaimers that apply to the journal pertain. 
Hydrogen Treatment and FeOOH overlayer: Effective approaches for enhancing the photoelectrochemical water oxidation performance of bismuth vanadate thin films

Aadesh P. Singh ${ }^{1,3, *}$, Nishant Saini ${ }^{1}$, Bodh R. Mehta ${ }^{1, *}$, Anders Hellman ${ }^{3}$, Beniamino Iandolo $^{2}$, Björn Wickman ${ }^{3}$

${ }^{1}$ Department of Physics, Indian Institute of Technology, Hauz Khas, New Delhi 110016, India ${ }^{2}$ Department of Micro- and Nanotechnology, Technical University of Denmark, $2800 \mathrm{Kgs}$. Lyngby, Denmark

${ }^{3}$ Division of Chemical Physics, Department of Physics, Chalmers University of Technology, SE-412 96 Göteborg, Sweden

\section{$\underline{\text { Graphical Abstract }}$}

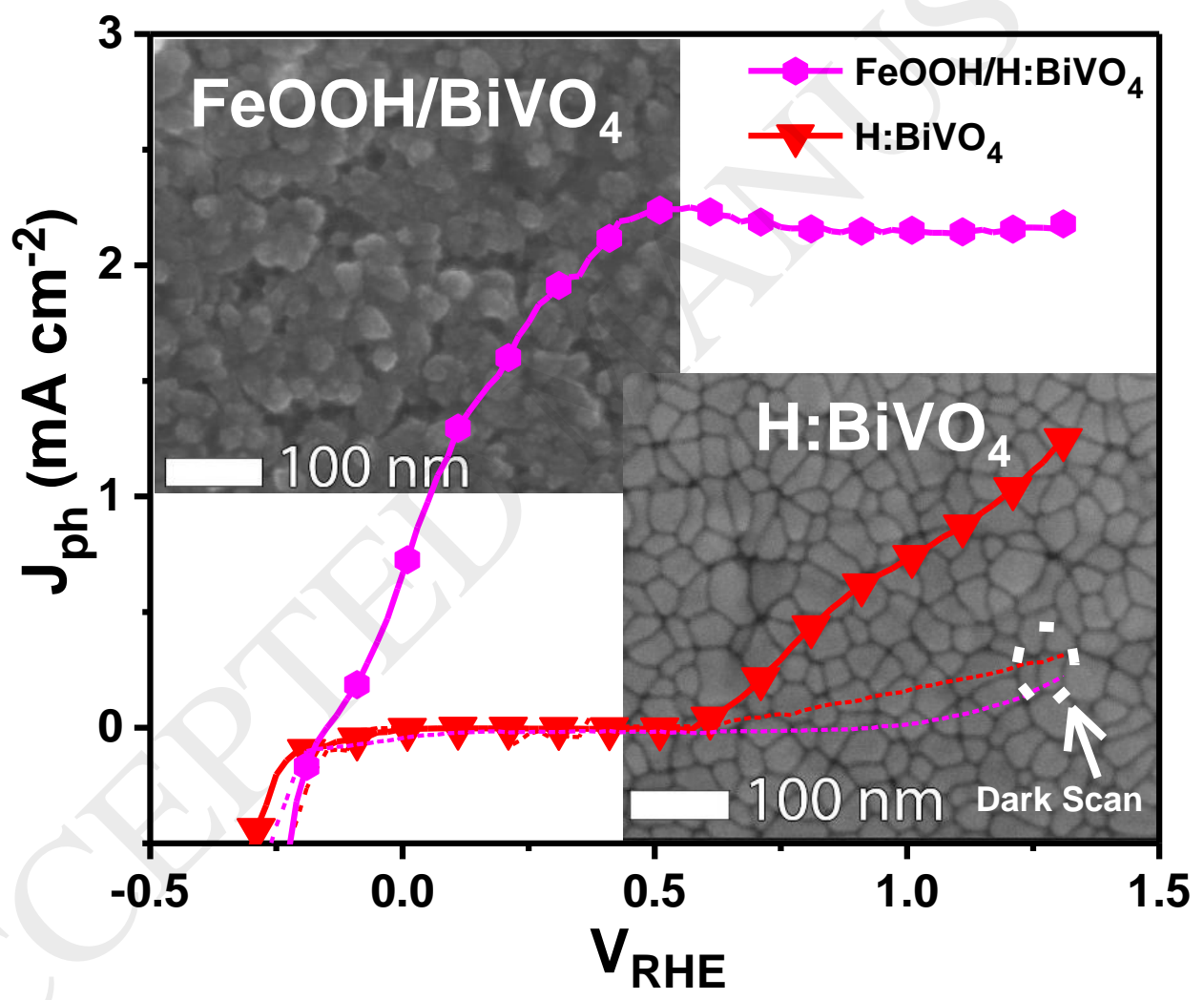




\title{
Highlights
}

- Dual modification, hydrogen treatment and $\mathrm{FeOOH}$ loading in rf-sputtered bismuth vanadate $\left(\mathrm{BiVO}_{4}\right)$ thin films.

- Iron oxyhydroxide, an oxygen evolution catalyst, improvement of the charge transport at the semiconductor/electrolyte interface.

- The resulting $\mathrm{FeOOH} / \mathrm{H}: \mathrm{BiVO}_{4}$ photoanode achieve a considerably higher photocurrent density $\left(\mathrm{J}_{\mathrm{p}} \sim 2.16 \mathrm{~mA} \mathrm{~cm}^{-2}\right.$ at $\left.1.23 \mathrm{~V}_{\mathrm{RHE}}\right)$.

- The enhanced photocurrent of $\mathrm{FeOOH} / \mathrm{H}: \mathrm{BiVO}_{4}$ photoanode is ascribed to an improved bulk charge transport.

- The dual modification strategy used here offers a simple but effective approach of improving the water oxidation performance of $\mathrm{BiVO}_{4}$.

\begin{abstract}
The water oxidation capability of the promising photoanode bismuth vanadate $\left(\mathrm{BiVO}_{4}\right)$ is hampered by poor bulk electron transport and by high rates of charge recombination at the semiconductor/electrolyte interface. Here, we demonstrate that a dual modification of $\mathrm{BiVO}_{4}$ by: (i) annealing in a hydrogen-containing environment and (ii) coating with $\mathrm{FeOOH}$ overlayer substantially enhances the water oxidation ability of $\mathrm{BiVO}_{4}$ photoanodes. Hydrogen treated, $\mathrm{FeOOH}$ coated $\mathrm{BiVO}_{4}$ photoanodes exhibit a water oxidation photocurrent density of $2.16 \mathrm{~mA}$ $\mathrm{cm}^{-2}$ at $1.23 \mathrm{~V}_{\mathrm{RHE}}$, which is 5 times higher than for untreated $\mathrm{BiVO}_{4}$ films. Moreover, they showed an impressive low photocurrent onset potential of $-0.11 \mathrm{~V}_{\mathrm{RHE}}$. A stable photocurrent was observed for $1 \mathrm{~h}$ of water oxidation measurement at $1.23 \mathrm{~V}_{\mathrm{RHE}}$ under 1 Sun illumination. The enhanced photocurrent of $\mathrm{FeOOH} / \mathrm{H}: \mathrm{BiVO}_{4}$ photoanode is ascribed to an improved bulk charge transport, as confirmed by impedance spectroscopy measurements and Mott-Schottky analysis. The cathodic shift of the onset potential originates from a lowering of the flat band potential and from an improvement of the charge transport at the semiconductor/electrolyte
\end{abstract}


interface. The dual modification strategy used here offers a simple but effective approach of improving the water oxidation performance of $\mathrm{BiVO}_{4}$.

Key Words: Bismuth vanadate, $\mathrm{FeOOH}$, hydrogen treatment, photoelectrochemical, solar hydrogen

\section{Introduction}

Artificial photosynthesis emerged as an alternative means to store solar energy in form of chemical bonds. Hydrogen production by photoelectrochemical (PEC) water splitting offers a particularly promising way of storing solar energy. The efficiency of hydrogen production in PEC water splitting is mainly dependent on the properties of photoactive materials used in PEC cell, i.e. the photoanode and/or photocathode [1]. In particular, the water oxidation half-cell reaction (hereinafter called oxygen evolution reaction, OER) is the one associated with most of the losses in PEC cells [2] and is therefore object of intense research.

Here, we examine $\mathrm{BiVO}_{4}$ as photoanode material for the OER since it has the following favorable properties: it can be synthesized by inexpensive methods [3-4]; it possesses an optical band gap (2.4-2.6 eV) that allows for harvesting of visible light [5]; and it has a valence band edge that is sufficiently positive to drive the OER [6]. The theoretical efficiency of solar to hydrogen conversion ( $\left.\eta_{\mathrm{STH}}\right)$ is over $9 \%$, corresponding to a photocurrent density up to $7.5 \mathrm{~mA}$ $\mathrm{cm}^{-2}$ under simulated AM 1.5 light irradiation [7-8]. However, the achieved applied bias photon-to-current efficiency (ABPE) is much lower $(1.75 \%$ at $0.6 \mathrm{~V}$ vs. RHE in case of nanoporous $\mathrm{BiVO}_{4}$ modified by $\mathrm{FeOOH} / \mathrm{NiOOH}$ dual-layer oxygen evolution catalysts) [9-10], due to the following factors: poor electron conduction (in spite of a lower effective electron mass than in e.g. $\mathrm{TiO}_{2}[11]$ ); high rates of bulk and surface recombination [12]; and slow OER kinetics [13].

Several efforts have recently been made to improve the energy conversion efficiency of $\mathrm{BiVO}_{4}$, with the goals of: (i) increasing light-absorption efficiency, (ii) reducing hole transport 
distance to match the diffusion length of holes, and (iii) achieving lower surface recombination rate than the OER rate. Strategies like n-type doping with $\mathrm{W}$ or Mo have shown beneficial effects on the charge transport properties [14-18]. On the other hand, unwanted change in $\mathrm{VO}_{4}$ tetrahedron chains can have a damaging effect on the OER of $\mathrm{BiVO}_{4}$ [19-20]. In recent years, annealing in hydrogen containing atmosphere offered a way of tailoring the optoelectronic properties of $\mathrm{BiVO}_{4}[4,21-22]$.

Additionally, coating $\mathrm{BiVO}_{4}$ with overlayers have been used to shift the OER onset potential cathodically, thus requiring a lower applied potential to initiate the OER. Many compounds have proven effective in this respect, such as $\mathrm{IrO}_{2}, \mathrm{RuO}_{2}, \mathrm{Co}-\mathrm{Pi}, \mathrm{Ni}-\mathrm{Bi}, \mathrm{FeOOH}$, and $\mathrm{NiOOH}$ [23-26]. The observed improvements can arise from one or more of the following effects: a higher turnover frequency for the OER, i.e. a co-catalytic effect, a reduction in surface recombination rate, an increased photovoltage and a lowered flat band potential. Among the various OECs, ferric oxyhydroxide $(\mathrm{FeOOH})$ has been studied by several groups due to its abundance on earth and stability of water oxidation properties in neutral and alkaline conditions. $\mathrm{FeOOH}$ has three main phases $(\alpha, \beta$ and $\gamma)$. It has been demonstrated that the $\mathrm{FeOOH}$ is a promising oxidation catalyst for PEC applications [24, 27-29]. Choi et al. [3, 9, 29] reported that $\gamma-\mathrm{FeOOH}$ is an efficient water oxidation catalyst for $\mathrm{BiVO}_{4}$ electrode. Most of these works utilised the either amorphous or $\alpha$-polymorph of $\mathrm{FeOOH}$, whereas very few reports are available on $\beta-\mathrm{FeOOH}$ (akaganéite), which is confirmed to be a semiconductor with a direct band gap of $2.12 \mathrm{eV}$ and can be used as a potential photocatalysts with a visible-light response [30].

In this work, we present a two-step modification approach to improve the PEC performance of $\mathrm{BiVO}_{4}$ thin films towards the OER by combining bulk and surface modification. Interestingly, both treatments (annealing in hydrogen containing atmosphere and $\mathrm{FeOOH}$ overlayer) result in an increase of photocurrent density and in a shift of OER onset potential. 
These two modifications bring about a synergistic effect, since we show that the two-step modification enhances the performance more than the individual modifications alone. In particular, the two-step modification leads to enhanced photocurrent density at $1.23 \mathrm{~V}_{\mathrm{RHE}}$ by a factor of 5 (from 0.42 to $2.16 \mathrm{~mA} \mathrm{~cm}^{-2}$ ), and to an OER onset potential shift by almost $1 \mathrm{~V}$ (from 0.95 to $-0.15 \mathrm{~V}_{\mathrm{RHE}}$ ). We employ physical and PEC characterization of the photoanodes to shed light on the mechanisms leading to the observed improvement in PEC performance.

\section{Experimental Section}

\subsection{Synthesis of $\mathrm{BiVO}_{4}$ thin films}

Pristine $\mathrm{BiVO}_{4}$ were deposited on indium-doped tin oxide $\left(\mathrm{SnO}_{2}: \mathrm{In}, \mathrm{ITO}\right)$ substrates by RFmagnetron sputtering using a bismuth vanadate target (Goodwill Metal Tech Co. Ltd., China; purity $99.99 \%$ ). Before deposition, ITO substrates of size $\approx 1.5 \mathrm{~cm} \times 1.0 \mathrm{~cm}$ were cleaned by sonication in acetone, ethanol and water, and finally dried in $\mathrm{N}_{2}$ gas flow. The sputtering chamber was initially pumped down to approximately $2.0 \times 10^{-6}$ Torr and then research grade Argon (flow rate $=20 \mathrm{sccm}$ ) was introduced into the chamber while maintaining the deposition pressure at $2.5 \times 10^{-2}$ Torr. Sputtering was carried out at a RF-power of $100 \mathrm{~W}$ at room temperature for $2 \mathrm{~h}$. After deposition, samples were annealed at $450{ }^{\circ} \mathrm{C}$ for $2 \mathrm{~h}$ in air to obtain the monoclinic phase of $\mathrm{BiVO}_{4}$.

\subsection{Hydrogen treatment and FeOOH deposition}

To improve the bulk properties of pristine $\mathrm{BiVO}_{4}$ thin films for enhanced photoelectrochemical activity properties of pristine $\mathrm{BiVO}_{4}$ thin films, the hydrogen treatment under partial pressure was carried out. For the hydrogen treatment under partial pressure, the annealing chamber was pumped down to $2.0 \times 10^{-6}$ Torr and $20 \mathrm{sccm} 5 \% \mathrm{H}_{2}$ balanced Ar was introduced into the chamber while maintaining the chamber pressure at $2 \times 10^{-2}$ Torr. The annealing temperature was set at $400{ }^{\circ} \mathrm{C}$ for $10 \mathrm{~h}$ followed by cooling down for $1 \mathrm{~h}$ [31]. Further, to modify the surface properties of $\mathrm{BiVO}_{4}$ and $\mathrm{H}: \mathrm{BiVO}_{4}$ thin films, a thin layer of $\beta-\mathrm{FeOOH}$ layer was deposited by electrodeposition 
technique based on our pervious report procedures with slightly changed deposition parameters for optimization of maximum photocurrent [32]. The electrodeposition of $\beta$-FeOOH was carried out in a three electrode assembly where $\mathrm{BiVO}_{4}$ coated indium doped tin oxide $\left(\mathrm{SnO}_{2}: \mathrm{In}\right.$, ITO) glass as used as working electrode, $\mathrm{Pt}$ wire as counter electrode and $\mathrm{Ag} / \mathrm{AgCl}$ saturated with $\mathrm{KCl}$ as reference electrode. The electrodeposition solution consisted of $5 \mathrm{mM} \mathrm{FeCl} \mathrm{Fe}_{3}+5$ $\mathrm{mM} \mathrm{KF}+0.1 \mathrm{M} \mathrm{KCl}+1 \mathrm{M} \mathrm{H}_{2} \mathrm{O}_{2}$ in Milli-Q water and cyclic voltammetry were performed in the potential range $0 \mathrm{~V}$ to $-0.3 \mathrm{~V}$ vs. $\mathrm{Ag} / \mathrm{AgCl}$ (sat. $\mathrm{KCl}$ ) with a sweep rate of $20 \mathrm{mV} \mathrm{s}^{-1}$ for 10 cycles at room temperature (Figure S1). The obtained samples were rinsed with mill-Q water and dried at room temperature to obtain the yellowish colored $\beta$-FeOOH layer over the $\mathrm{BiVO}_{4}$ and $\mathrm{H}: \mathrm{BiVO}_{4}$ samples as shown in inset of Figure 2a.

\subsection{Material Characterization}

X-ray diffraction patterns were obtained using a Phillips X'Pert Pro setup with $\mathrm{Cu}-\mathrm{K} \alpha$ radiation $(\lambda=1.5418 \AA)$ operated at $45 \mathrm{kV}$ and $40 \mathrm{~mA}$. Raman spectroscopic signatures were obtained by employing a LabRAM HR evolution Raman microscope. Scanning electron microscope (SEM) images were acquired using a Supra 60 VP microscope (Zeiss) operated at an acceleration voltage of $10 \mathrm{kV}$. UV-visible spectroscopic measurements were performed with a LAMBDA $1050 \mathrm{UV} / \mathrm{vis} / \mathrm{NIR}$ spectrophotometer. To check the chemical state of the elements on the surface of pristine $\mathrm{BiVO}_{4}, \mathrm{H}: \mathrm{BiVO}_{4}$ and $\mathrm{FeOOH} / \mathrm{BiVO}_{4}$ samples, X-Ray photoelectron spectroscopy (XPS) measurements were carried out on a PerkinElmer PHI 5000C ESCA system (base pressure $\sim 10^{-10}$ mbar) using monochromatic $\mathrm{Al} \mathrm{K \alpha}$ radiation. All spectra were calibrated using the $\mathrm{C} 1 \mathrm{~s}$ photoelectron component peak of amorphous carbon $(284.8 \mathrm{eV})$ present in the sample.

\subsection{PEC Characterization}

The PEC measurements were performed in a three-electrode configuration on $\mathrm{BiVO}_{4}$ films employed as working electrode, $\mathrm{Pt}$ as counter electrode and $\mathrm{Ag} / \mathrm{AgCl}$ as reference electrode. 
The $0.1 \mathrm{M} \mathrm{Na}_{2} \mathrm{SO}_{4}(\mathrm{pH}=7)$ was used as an electrolyte and prepared by adding the desired amount of $\mathrm{Na}_{2} \mathrm{SO}_{4}$ in milli-Q water followed by starring for $1 \mathrm{hr}$ at room temperature. The PEC cell was controlled using an Autolab Electrochemical Workstation (X-Pot Potentiostat). A $150 \mathrm{~W}$ Xe arc lamp with total power density of $100 \mathrm{~mW} \mathrm{~cm}^{-2}$ equipped with a AM1.5 filter was used as light source. Linear sweep voltammetry scans under dark and illumination were measured in the potential range -1.0 to $+1.0 \mathrm{~V} v s$. $\mathrm{Ag} / \mathrm{AgCl}$ with a scan rate of $20 \mathrm{mV} \mathrm{s}^{-1}$. The working electrode potential with respect to saturated $\mathrm{Ag} / \mathrm{AgCl}$ was converted to reversible hydrogen electrode (RHE) using the following formula [33]: $E_{R H E}=E_{A g / A g C l}+0.059 p H+E_{A g / A g C l}$, where $\mathrm{E}_{\mathrm{Ag} / \mathrm{AgCl}}=0.199 \mathrm{~V}$. Electrochemical impedance spectroscopy (EIS) measurements were carried out under 1 Sun simulated illumination in the frequency range from $10^{5}$ to $0.1 \mathrm{~Hz}$ with AC signal amplitude of $10 \mathrm{mV}$. The capacitance-voltage profiles were determined at an applied AC voltage with a frequency of $1 \mathrm{kHz}$ in the dark, and Mott-Schottky plots $\left(\mathrm{C}^{-2} v s . \mathrm{V}_{\text {app }}\right)$ were generated by employing a common procedure in the literature [34].

\section{Result and Discussion}

The formation and preservation of monoclinic phase of $\mathrm{BiVO}_{4}\left(\mathrm{JCPDS}^{83-1698)}\right.$ crystal structure before and after hydrogen treatment and $\mathrm{FeOOH}$ deposition can be induced from the XRD patterns (Figure S2) and Raman spectra (Figure S3). Some additional XRD peaks with relatively high intensities are assigned to the underlying ITO substrate (JCPDS 06-0416), as indicated in Figure S2. The XRD patterns of the $\mathrm{FeOOH} / \mathrm{BiVO}_{4}$ and $\mathrm{FeOOH} / \mathrm{H}: \mathrm{BiVO}_{4}$ samples indicate that $\beta-\mathrm{FeOOH}$ is also present, with peaks at $27.98^{\circ}, 30.52^{\circ}, 41.72^{\circ}$ and $46.09^{\circ}$ (the two peaks at $30.52^{\circ}$ and $46.09^{\circ}$ overlap with the relatively strong peak from the $\mathrm{BiVO}_{4}$ layer). Further evidence of the presence of $\mathrm{FeOOH}$ is given by the Raman spectra. In addition to the Raman vibrational modes at around $129 \mathrm{~cm}^{-1}, 210 \mathrm{~cm}^{-1}, 324 \mathrm{~cm}^{-1}, 364 \mathrm{~cm}^{-1}, 640 \mathrm{~cm}^{-1}$ and 829 $\mathrm{cm}^{-1}$ (corresponding to $\mathrm{BiVO}_{4}$ ) [35], an additional peak at $720 \mathrm{~cm}^{-1}$ (Figure S3), characteristic of $\beta$-FeOOH [36], was observed. 
The surface morphology of pristine $\mathrm{BiVO}_{4}, \mathrm{H}: \mathrm{BiVO}_{4}$ and $\mathrm{FeOOH} / \mathrm{BiVO}_{4}$ composite films is shown in Figure 1. All films show a homogeneous coverage of the ITO substrate. The pristine $\mathrm{BiVO}_{4}$ film (Figure 1a) shows dense aggregates of irregularly shaped $\mathrm{BiVO}_{4}$ grains (with characteristic dimension of 30-40 nm) forming a coarse surface, similar to previously reported $\mathrm{BiVO}_{4}$ films [37]. Hydrogen treatment at $400^{\circ} \mathrm{C}$ results in larger grains with sharp grain boundaries (Figure 1b). A significant change in surface morphology with noticeable small valleys and hills is observed when $\beta-\mathrm{FeOOH}$ was electrodeposited (Figure 1c) on $\mathrm{BiVO}_{4}$. The morphology of the electrodeposited $\mathrm{FeOOH}$ on $\mathrm{BiVO}_{4}$ film (Figure 1c) appears to have a thin layer of $\beta-\mathrm{FeOOH}$ crystallites with larger, sharp edge particles of $\mathrm{BiVO}_{4}$ (ca. $30-40 \mathrm{~nm}$ diameter) in the background. The cross-sectional view of SEM image (Figure S4) displays a dense and homogeneous morphology and the estimated film thickness is approximately 250 nm.
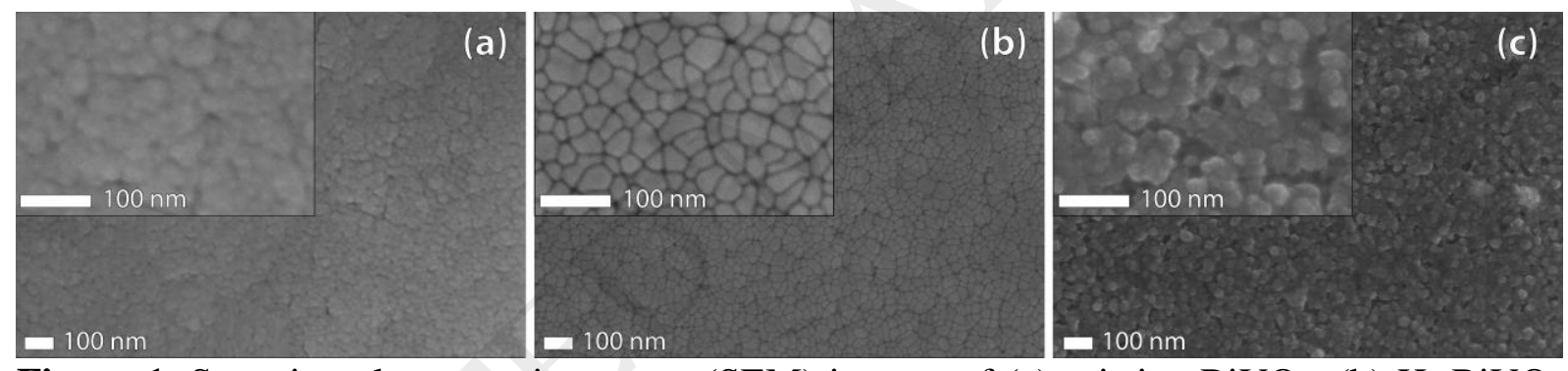

Figure 1. Scanning electron microscopy (SEM) images of (a) pristine $\mathrm{BiVO}_{4}$, (b) $\mathrm{H}$ : $\mathrm{BiVO}_{4}$ and (c) $\mathrm{FeOOH} / \mathrm{BiVO}_{4}$ thin films deposited on ITO coated glass. Inset of (b) and (c) show higher magnification images of $\mathrm{H}: \mathrm{BiVO}_{4}$ and $\mathrm{FeOOH} / \mathrm{BiVO}_{4}$, respectively.

The optical absorbance spectra were measured using UV-vis spectroscopy and the spectra recorded in the wavelength range between $300 \mathrm{~nm}$ and $1100 \mathrm{~nm}$ is presented in Figure 2a. All samples show strong absorption in the near UV, and partially in the visible light region. This is supported by the fact that the samples appear yellow (inset (i) of Figure 2a). A slightly darker color (inset (ii) of Figure 2a) can be seen on $\mathrm{H}: \mathrm{BiVO}_{4}$ samples as a result of the hydrogen treatment. The absorption edge for pristine $\mathrm{BiVO}_{4}$ is observed in the visible-light region at $\sim 475$ $\mathrm{nm}$, which is characteristic of monoclinic $\mathrm{BiVO}_{4}$ [38]. After hydrogen treatment and $\mathrm{FeOOH}$ 
deposition, a red shift in absorption edge to $500 \mathrm{~nm}$ is observed. The band gap energy for all the samples was determined using the equation, $(\alpha h v)=A\left(h v-E_{g)}\right)^{n}$, where $\alpha$ is absorption coefficient, $A$ is a constant, $h$ is Planck's constant, $v$ is the frequency of incident light, $E_{g}$ is the band gap energy of the material and $n$ is a constant related to the type of optical transition $(n=$ 2 for indirect band gap and $n=1 / 2$ for direct band gap). Since $\mathrm{BiVO}_{4}$ is a direct band gap semiconductor [39], a graph of $(\alpha h v)^{2} v s . h v$ was plotted for all the samples as shown in Figure 2b. Extrapolation of the linear portion of the graph yielded an intercept on the $h v$ axis that corresponds to an energy band gap of 2.66 and $2.60 \mathrm{eV}$ for pristine and $\mathrm{H}: \mathrm{BiVO}_{4}$ samples, respectively. The FeOOH coated samples showed a slightly reduced band gap of 2.63 and 2.52 $\mathrm{eV}$ for $\mathrm{FeOOH} / \mathrm{BiVO}_{4}$ and $\mathrm{FeOOH} / \mathrm{H}: \mathrm{BiVO}_{4}$ samples (Figure 2b), respectively.
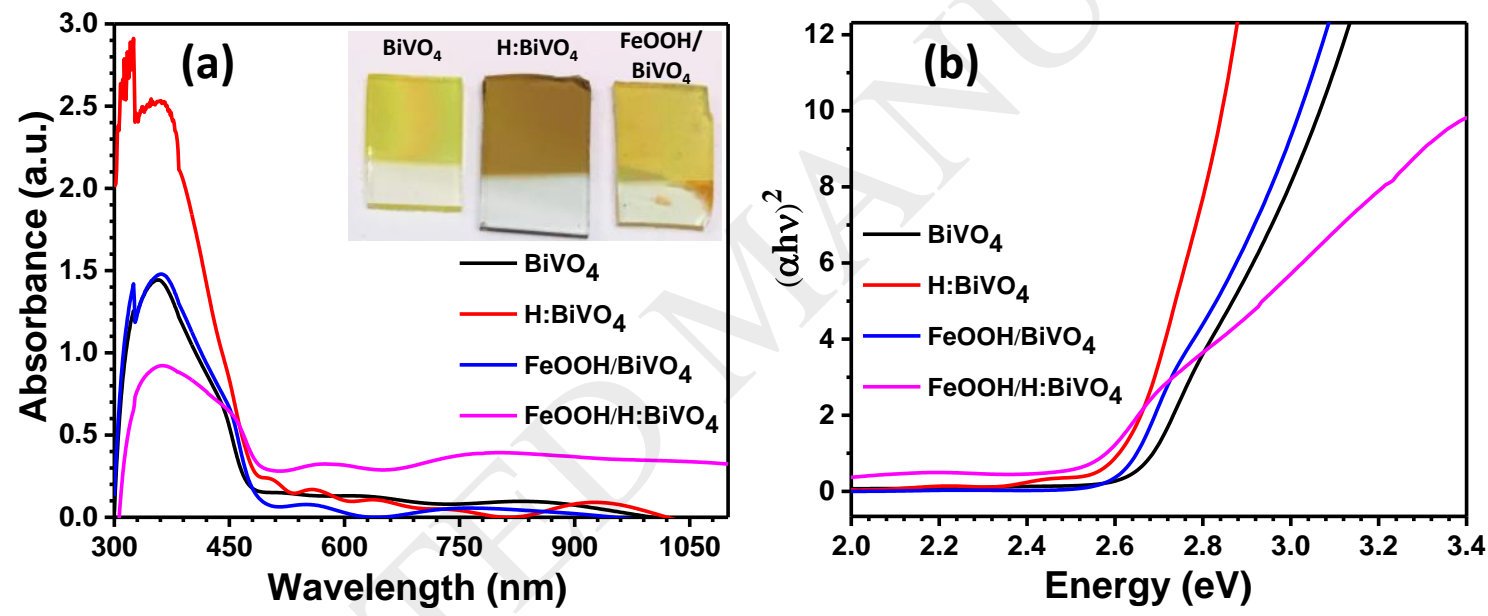

Figure 2: (a) UV-vis-NIR absorption spectra and (b) Tauc's plot for $\mathrm{BiVO}_{4}, \mathrm{H}: \mathrm{BiVO}_{4}$, $\mathrm{FeOOH} / \mathrm{BiVO}_{4}$ and $\mathrm{FeOOH} / \mathrm{H}: \mathrm{BiVO}_{4}$ thin films samples. Inset of (a) shows the digital picture of (i) $\mathrm{BiVO}_{4}$, (ii) $\mathrm{H}: \mathrm{BiVO}_{4}$ and (iii) $\mathrm{FeOOH} / \mathrm{BiVO}_{4}$ samples.

In order to study the chemical modification of $\mathrm{BiVO}_{4}$ with hydrogen treatment and after FeOOH deposition, XPS measurements were carried out on pristine $\mathrm{BiVO}_{4}, \mathrm{H}: \mathrm{BiVO}_{4}$, $\mathrm{FeOOH} / \mathrm{BiVO}_{4}$ and $\mathrm{FeOOH} / \mathrm{H}: \mathrm{BiVO}_{4}$ samples. Figure $3 \mathrm{a}$ and $3 \mathrm{~b}$ show the core levels of $\mathrm{Bi}(4 \mathrm{f})$ and $\mathrm{V}(2 \mathrm{p})$ XPS spectra of the $\mathrm{BiVO}_{4}$ and $\mathrm{H}: \mathrm{BiVO}_{4}$ samples, respectively. The $\mathrm{Bi}\left(4 \mathrm{f}_{5 / 2}\right)$ and $\mathrm{Bi}\left(4 \mathrm{f}_{7 / 2}\right)$ lines were found at the binding energy values of 164.2 and $158.9 \mathrm{eV}$ in $\mathrm{BiVO}_{4}$ and $\mathrm{H}: \mathrm{BiVO}_{4}$ samples, respectively (Figure 3a). Also, the $\mathrm{V}\left(2 \mathrm{p}_{1 / 2}\right)$ and $\mathrm{V}\left(2 \mathrm{p}_{3 / 2}\right)$ lines were found at 
the binding energy values of 523.5 and $515.9 \mathrm{eV}$ in $\mathrm{BiVO}_{4}$ and $\mathrm{H}: \mathrm{BiVO}_{4}$ samples, respectively (Figure 3b). According to Silversmit et al., [40] the $\mathrm{V}\left(2 \mathrm{p}_{3 / 2}\right)$ position for the $\mathrm{V}^{5+}$ and $\mathrm{V}^{4+}$ states should be located at about 517.2 and $515.8 \mathrm{eV}$, respectively. In both, pristine and $\mathrm{H}: \mathrm{BiVO}_{4}$ samples, the $\mathrm{V}\left(2 \mathrm{p}_{3 / 2}\right)$ peak is found at $515.9 \mathrm{eV}$, which matches very well with $\mathrm{V}^{4+}$ state. Thus, it appears as the hydrogen treatment does not affect the oxidation state of $\mathrm{V}$ in $\mathrm{BiVO}_{4}$ state (Figure 3b). However, in a few studies it has been reported that hydrogen treatment can create additional oxygen vacancies in metal oxide semiconductors, which results in partial reduction, i.e. $\mathrm{Ti}^{4+}$ to $\mathrm{Ti}^{3+}$ in case of $\mathrm{TiO}_{2}, \mathrm{Fe}^{3+}$ to $\mathrm{Fe}^{2+}$ in case of hematite and $\mathrm{V}^{5+}$ to $\mathrm{V}^{4+}$ for $\mathrm{BiVO}_{4}$, [4144]. Figure $3 \mathrm{c}$ show the core-level $\mathrm{O}(1 \mathrm{~s})$ spectra of $\mathrm{BiVO}_{4}$ and $\mathrm{H}: \mathrm{BiVO}_{4}, \mathrm{FeOOH} / \mathrm{BiVO}_{4}$ and $\mathrm{FeOOH} / \mathrm{H}: \mathrm{BiVO}_{4}$. Pristine $\mathrm{BiVO}_{4}$ sample exhibits two distinct peaks at binding energy of 529.5 and $530.9 \mathrm{eV}$. The value of $529.5 \mathrm{eV}$ observed in all samples is consistent with the value reported for $\mathrm{BiVO}_{4}$. The hydrogen treated $\mathrm{BiVO}_{4}$ exhibits a relatively lower peak intensity at $529.5 \mathrm{eV}$ (in comparison to the higher peak intensity at $530.9 \mathrm{eV}$ in pristine $\mathrm{BiVO}_{4}$ ) indicating that the concentration of hydroxyl groups on $\mathrm{H}: \mathrm{BiVO}_{4}$ surface was decreased by the annealing in hydrogen atmosphere. However, the relative high intensity of $\mathrm{O}(1 \mathrm{~s})$ peak in $\mathrm{FeOOH} / \mathrm{BiVO}_{4}$ in comparison to the pristine $\mathrm{BiVO}_{4}$ shows that the concentration of hydroxyl groups is high, which is consistent with previous reports on $\mathrm{FeOOH}$ (for which the $\mathrm{OH}$ peak makes up about $45 \%$ of the total O(1s) peak area) [45-46]. Further, the Fe(2p) XPS spectra (Figure 3d) collected on the $\mathrm{FeOOH} / \mathrm{BiVO}_{4}$ and $\mathrm{FeOOH} / \mathrm{H}: \mathrm{BiVO}_{4}$ samples show the presence of $\mathrm{Fe}^{3+}$ species on the surface of $\mathrm{BiVO}_{4}$. Therefore, the XPS result confirms the presence of a thin layer of FeOOH over the $\mathrm{BiVO}_{4}$. 

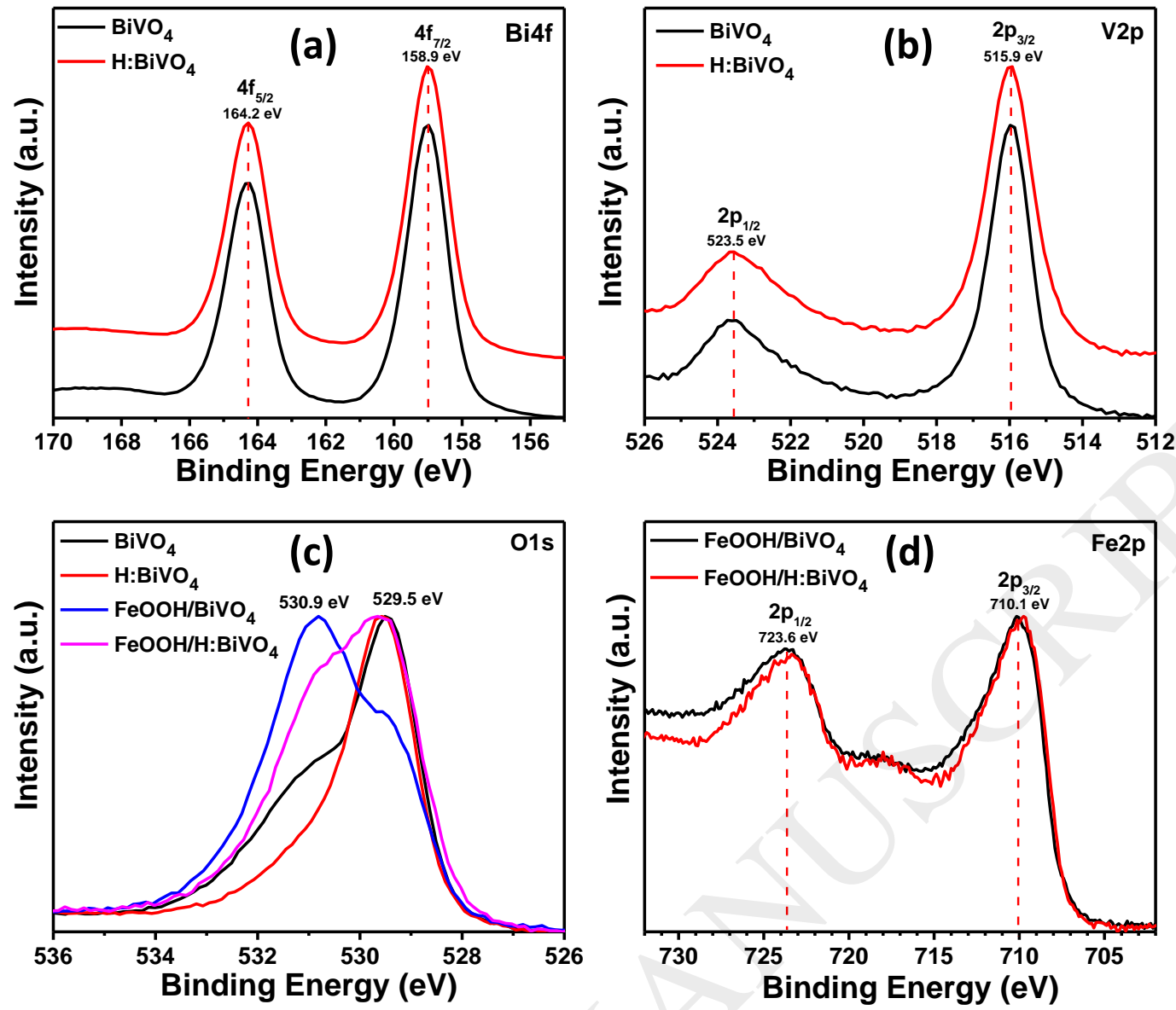

Figure 3. (a) Fitted XPS core level spectra for (a) $\mathrm{Bi}(4 \mathrm{f})$ (b) $\mathrm{V}\left(2 \mathrm{p}\right.$ ) for pristine $\mathrm{BiVO}_{4}$ and $\mathrm{H}: \mathrm{BiVO}_{4}$, thin films. (c) Fitted $\mathrm{O}(1 \mathrm{~s})$ core level spectra for pristine $\mathrm{BiVO}_{4}, \mathrm{H}: \mathrm{BiVO}_{4}$, $\mathrm{FeOOH} / \mathrm{BiVO}_{4}$ and $\mathrm{FeOOH} / \mathrm{H}: \mathrm{BiVO}_{4}$ and (d) $\mathrm{Fe}\left(2 \mathrm{p}\right.$ ) spectra for $\mathrm{FeOOH} / \mathrm{BiVO}_{4}$ and $\mathrm{FeOOH} / \mathrm{H}: \mathrm{BiVO}_{4}$ thin films.

The effect of hydrogen treatment and surface modification by $\mathrm{FeOOH}$ on the PEC performance of the $\mathrm{BiVO}_{4}$ photoanodes was determined by measuring the photocurrent density under steady state and chopped light illumination. The cyclic voltammetry curves measured under dark condition for bare ITO, pristine $\mathrm{BiVO}_{4}$ and $\mathrm{FeOOH}$ on ITO substrate are shown in Figure S5. The photocurrent density versus applied potential $\left(J_{p h}-V_{a p p}\right)$ curves obtained under steady state illumination condition are shown in Figure 4a and the photocurrent onset potential is obtained from the Butler plots shown in Figure S6. All the photoanodes shows anodic photocurrent as expected thanks to the n-type characteristic of $\mathrm{BiVO}_{4}$. The pristine $\mathrm{BiVO}_{4}$ photoanode exhibits quite poor PEC response with a photocurrent density of $0.42 \mathrm{~mA} \mathrm{~cm}{ }^{-2}$ at $1.23 \mathrm{~V}_{\mathrm{RHE}}$ and an onset potential of $0.95 \mathrm{~V}_{\mathrm{RHE}}$. The low photocurrent density and highly anodic 
onset potential are likely due to high bulk charge recombination rate, and high surface recombination rate and/or low OER rate, respectively [47]. Hydrogen treatment leads to an increase of photocurrent density (from 0.42 to $1.06 \mathrm{~mA} \mathrm{~cm}^{-2}$ at $1.23 \mathrm{~V}_{\mathrm{RHE}}$ ) and a cathodic shift of onset potential (from $0.95 \mathrm{~V}_{\mathrm{RHE}}$ to $0.61 \mathrm{~V}_{\mathrm{RHE}}$ ). Hydrogen treatment in $\mathrm{BiVO}_{4}$ at $400{ }^{\circ} \mathrm{C}$ was found to yield the best PEC performance in our previous study [4]. These results are also in agreement with earlier work showing that the incorporation of hydrogen leads to a shift in Fermi level toward the conduction band edge while maintaining the n-type character of $\mathrm{BiVO}_{4}[23]$.
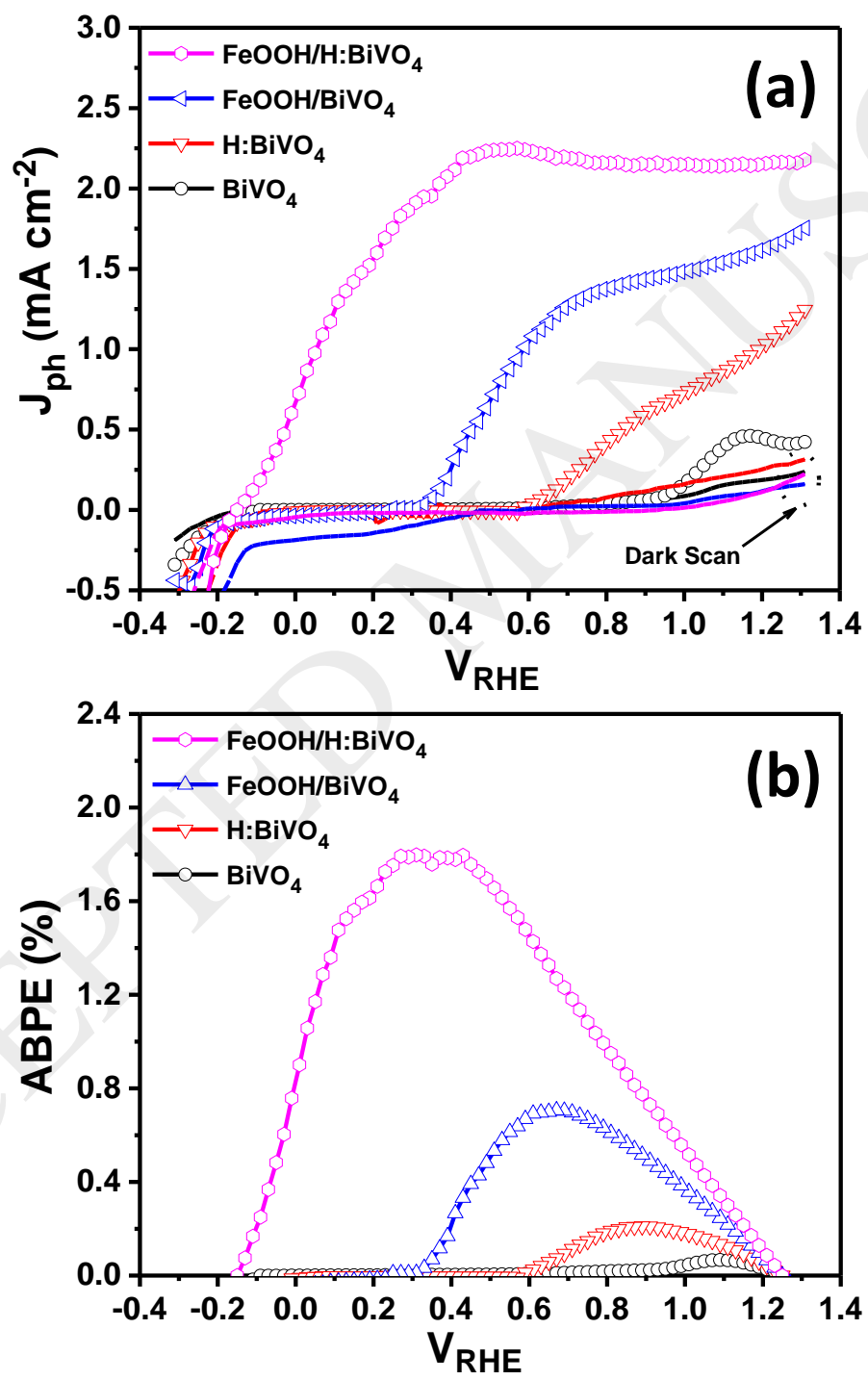

Figure 4: (a) Linear sweep voltammograms and (b) Calculated applied bias photon-to-current conversion efficiency for the pristine $\mathrm{BiVO}_{4}, \mathrm{H}: \mathrm{BiVO}_{4}, \mathrm{FeOOH} / \mathrm{BiVO}_{4}$ and $\mathrm{FeOOH} / \mathrm{H}: \mathrm{BiVO}_{4}$ photoanodes as a function of applied potential vs RHE measures in $0.1 \mathrm{M} \mathrm{Na}_{2} \mathrm{SO}_{4}$ under $1 \mathrm{Sun}$ illumination. 
The surface modification by $\mathrm{FeOOH}$ leads to a further cathodic shift of onset potential and to a significantly higher photocurrent (Figure 4a and Table S1). Deposition of FeOOH on pristine $\mathrm{BiVO}_{4}$ lowered the photocurrent onset potential up to $0.32 \mathrm{~V}_{\mathrm{RHE}}$ and generated water oxidation photocurrents of $1.66 \mathrm{~mA} \mathrm{~cm}^{-2}$ at $1.23 \mathrm{~V}_{\mathrm{RHE}}$. The increase in photocurrent is most likely thanks to the improved bulk charge transport [16-17, 25], as will be confirmed by EIS analysis. After the deposition of $\mathrm{FeOOH}$ on the surface of $\mathrm{H}: \mathrm{BiVO}_{4}$, the $\mathrm{FeOOH} / \mathrm{H}: \mathrm{BiVO}_{4}$ photoanode shows an further enhancement in photocurrent density to $2.16 \mathrm{~mA} \mathrm{~cm}^{-2}$ at 1.23 $\mathrm{V}_{\text {RHE}}$. Also, the $\mathrm{FeOOH} / \mathrm{H}: \mathrm{BiVO}_{4}$ photoanode has a remarkably low onset potential of -0.15 $\mathrm{V}_{\text {RHE. }}$ The similar trend in photocurrent density is also obtained under the chopped light illumination. Figure S7 represents the transient photocurrent spectra measurements under chopped illumination at $1.23 \mathrm{~V}_{\mathrm{RHE}}$ for all the four photoelctrodes. From the transient photocurrent spectra it is clear that no significant photocurrent can be observed as soon as the light turned off and the light on-off cycles are reproducible.

Additionally, we have calculated the applied bias photon-to-current conversion efficiency (ABPE) for all samples by using following equation [48]:

$$
\mathrm{ABPE}=J_{P}\left(\frac{1.23-V_{A p p}}{I_{o}}\right) \times 100
$$

where $J_{p}$ is the photocurrent density at the applied bias, $V_{a p p}$ is the applied bias (vs. RHE), and $I_{o}$ is the power density of the incident light. The ABPE for all photoanodes calculated by using the $J_{p h}-V_{a p p}$ curves are plotted as function of $V_{a p p}$ and shown in Figure $4 \mathrm{~b}$. The pristine $\mathrm{BiVO}_{4}$ shows an $\mathrm{ABPE}$ of $0.07 \%$ at $1.1 \mathrm{~V}_{\text {RHE}}$. The $\mathrm{H}: \mathrm{BiVO}_{4}$ exhibits a 3-fold improvement in maximum $\mathrm{ABPE}\left(0.21 \%\right.$ at $\left.0.9 \mathrm{~V}_{\mathrm{RHE}}\right)$. The $\mathrm{FeOOH}$ loading on pristine $\mathrm{BiVO}_{4}$ and $\mathrm{H}: \mathrm{BiVO}_{4}$ samples significantly enhances ABPE. Addition of $\mathrm{FeOOH}$ on pristine $\mathrm{BiVO}_{4}$ achieves an ABPE of $0.7 \%$ at $0.65 \mathrm{~V}_{\mathrm{RHE}}$. The highest photoconversion efficiency of $1.73 \%$ at a significantly lower potential of $0.23 \mathrm{~V}_{\mathrm{RHE}}$ is achieved with $\mathrm{FeOOH}$ on $\mathrm{H}: \mathrm{BiVO}_{4}$. 
Furthermore, we have evaluated the photoactivity of the samples under a constant applied potential of $1.23 \mathrm{~V}_{\mathrm{RHE}}$ using chopped light as shown in Figure S7. Initially, when switching on the light, an anodic spike of photocurrent was observed in all the samples followed by a stable photocurrent. The photocurrent values increased from $0.46 \mathrm{~mA} \mathrm{~cm}^{-2}$ for pristine $\mathrm{BiVO}_{4}$ to $1.06 \mathrm{~mA} \mathrm{~cm}{ }^{-2}$ for $\mathrm{H}: \mathrm{BiVO}_{4}$ and $1.92 \mathrm{~mA} \mathrm{~cm}{ }^{-2}$ after $\mathrm{FeOOH}$ deposition on $\mathrm{BiVO}_{4}$. The stabilized photocurrent reached $2.34 \mathrm{~mA} \mathrm{~cm}{ }^{-2}$ for $\mathrm{FeOOH} / \mathrm{H}: \mathrm{BiVO}_{4}$. These values agree well with those determined from the $J_{p h}-V_{a p p}$ characteristics under continuous light illumination (Figure 4a). Longer measurements with dual modified, hydrogen treatment and $\mathrm{FeOOH}$ loading, $\mathrm{BiVO}_{4}$ photoanodes show that the improvement in photocurrent persists at least for $\sim 1$ h (Figure S8).

After the PEC measurements, Mott-Schottky analysis was performed on all samples. From the Mott-Schottky plots (Figure 5), the charge carrier density and flat band potentials were calculated using the Mott-Schottky equation [49]:

$$
\frac{1}{C^{2}}=\left(\frac{2}{q \varepsilon_{o} \varepsilon N_{D} A^{2}}\right)\left(V_{A P P}-V_{F B}-\frac{k T}{q}\right)
$$

where $C$ is the space charge capacitance, $q$ is the electron charge, $\varepsilon$ is the dielectric permittivity of vacuum, $\varepsilon=68$ is the relative dielectric constant of $\mathrm{BiVO}_{4}[50], N_{D}$ is the donor density $\left(\mathrm{cm}^{-}\right.$ $\left.{ }^{3}\right), V_{a p p}$ is the electrode potential applied, $V_{F B}$ is the flat band potential, $k$ is the Boltzmann's constant, and $T$ is the absolute temperature. The donor density can be calculated from the slopes of Mott-Schottky curve using the equation $\mathrm{N}_{\mathrm{D}}=2 /\left(\mathrm{q} \varepsilon_{\mathrm{o}} \varepsilon\right)\left[\mathrm{d}\left(1 / \mathrm{C}^{2}\right) / \mathrm{dV}\right]^{-1}$. The calculated values of $N_{d}$ increases from $2.37 \times 10^{17}$ in the $\mathrm{BiVO}_{4}$ sample to $5.15 \times 10^{17}$ in the $\mathrm{H}: \mathrm{BiVO}_{4}$ sample, then further increases to $9.80 \times 10^{18}$ and $1.24 \times 10^{20}$ for $\mathrm{FeOOH} / \mathrm{BiVO}_{4}$ and $\mathrm{FeOOH} / \mathrm{H}: \mathrm{BiVO}_{4}$, respectively. As a consequence of the changes in $N_{D}$, the width $L_{d}$ of the space-charge layer at the photoelectrode/electrolyte interface changed according to the following relationship: $\mathrm{L}_{\mathrm{D}}=$ $\left[\left(2 \varepsilon_{\mathrm{o}} \varepsilon\right) /(\mathrm{qN})\left(\mathrm{V}-\mathrm{V}_{\mathrm{FB}}\right)\right]^{1 / 2}$ (see Table $\mathrm{S} 2$ for calculated values). The flat band potentials can be determined from the extrapolation of linear fit of Mott-Schottky plots with the x-axis. The flat- 
band potential $\left(V_{F B}\right)$ of the $\mathrm{FeOOH} / \mathrm{H}: \mathrm{BiVO}_{4}$ photoanode was calculated to be $-0.15 \mathrm{~V}_{\mathrm{RHE}}$ as shown in Figure 5, which is about $500 \mathrm{mV}$ more negative than pristine $\mathrm{BiVO}_{4}$. A more negative $V_{F B}$ is beneficial for anodic reactions such as the OER. A decrease in $V_{F B}$ leading to cathodic shift of OER onset potential has recently been observed for $\mathrm{Fe}_{2} \mathrm{O}_{3}$ photoanodes after prolonged oxidation treatments [51]. We highlight here that for our samples, the difference between onset potential and $V_{F B}$ is actually increasing in the following order: $\mathrm{BiVO}_{4}>\mathrm{H}: \mathrm{BiVO}_{4}>$ $\mathrm{FeOOH} / \mathrm{BiVO}_{4}>\mathrm{FeOOH} / \mathrm{H}: \mathrm{BiVO}_{4}$. This is an indication that there are further mechanisms than just a lowering of $V_{F B}$ (suppression of surface recombination, increase of OER rate, increase of photovoltage), leading to the cathodic shift of onset potential. Interestingly, the difference between onset potential and $V_{F B}$ for the $\mathrm{FeOOH} / \mathrm{H}: \mathrm{BiVO}_{4}$ sample is as small as 40 $\mathrm{mV}$, which suggests that we are close to exploiting the full potential of $\mathrm{BiVO}_{4}$ in terms of bias needed to initiate the OER.

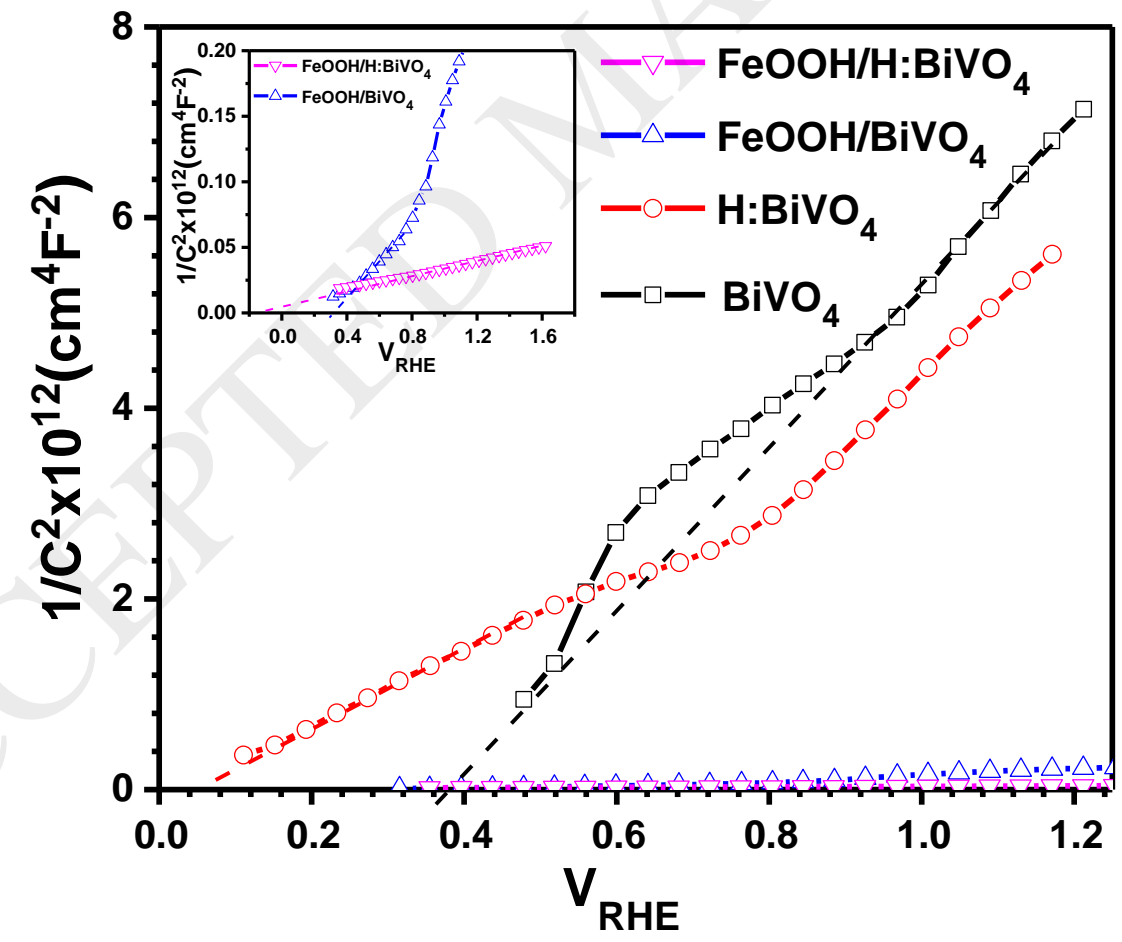

Figure 5: Mott-Schottky plots of $\mathrm{BiVO}_{4}, \mathrm{H}: \mathrm{BiVO}_{4}, \mathrm{FeOOH} / \mathrm{BiVO}_{4}$ and $\mathrm{FeOOH} / \mathrm{H}: \mathrm{BiVO}_{4}$ under dark in $0.1 \mathrm{M} \mathrm{Na}_{2} \mathrm{SO}_{4}(\mathrm{pH} 7)$ using a three-electrode system

Finally, the results from EIS are summarized in Figure 6a in the form of Nyquist plots (i.e. negative imaginary vs. real component of the total impedance $Z$ ). The total impedance 
follows the trend: $\mathrm{BiVO}_{4}>\mathrm{H}: \mathrm{BiVO}_{4}>\mathrm{FeOOH} / \mathrm{BiVO}_{4}>\mathrm{FeOOH} / \mathrm{H}: \mathrm{BiVO}_{4}$. Such trend if commensurate with the performance of the electrodes in terms of $J_{p h^{-}} V_{a p p}$ curves. The traces for the samples with and without $\mathrm{FeOOH}$ show two and one semicircle, respectively. For this reason, we chose different equivalent circuits to perform data fit. For the samples without $\mathrm{FeOOH}$, we used a modification of the Randle's circuit (see the yellow dashed box in Figure $6 b$, characterized by a resistance $R_{s}$ in series with the parallel of another resistance $R_{1}$ and a constant phase element $\mathrm{CPE}_{1}$. For the samples including $\mathrm{FeOOH}$, we used the circuit enclosed in the green dashed box of Fig. $6 \mathrm{~b}$. This circuit has an additional parallel of a resistance $\mathrm{R}_{2}$ and a constant phase element $\mathrm{CPE}_{2}$. We chose CPE's instead of pure capacitances owing to the better data fit. The impedance of a CPE is a hybrid between a resistor and a capacitor and CPE's are used often to describe capacitors with non-uniform spatial properties. It is nonetheless possible to calculate an effective capacitance from the CPE parameters and from the respective parallel resistance. Results from the fitting are summarized in the table in Figure 6c. The hydrogen treatment results in decrease of $\mathrm{R}_{1}$ of a factor 14 and 44 for samples with and without $\mathrm{FeOOH}$, respectively. Since $\mathrm{R}_{1}$ corresponds to the charge transport resistance in $\mathrm{BiVO}_{4}$, this is a confirmation of the beneficial role of the hydrogen treatment on the bulk charge transport, i.e. within $\mathrm{BiVO}_{4}$. Interestingly, the hydrogen treatment on samples containing $\mathrm{FeOOH}$ also reduced the resistance $R_{2}$ of a factor of 5 . Since $R_{2}$ is the resistance associated with charge transfer at the electrode/electrolyte interface, this is an indication that hydrogen treated $\mathrm{BiVO}_{4}$ forms a junction with $\mathrm{FeOOH}$ of higher quality with respect to charge transport. It is worth mentioning that these measurements are not conclusive in determining whether the observed shift in onset potential originates from a reduced surface recombination rate, or by an increase of the OER, or by both. The role of overlayers such as FeOOH is not completely understood yet, as they sometimes appear to behave as true catalysts (i.e. increase the OER rate), and sometimes as suppressors of surface recombination [52], depending on which photoabsorber 
they are deposited, as well as fabrication conditions. Elucidating the mechanism(s) behind the beneficial effect of $\mathrm{FeOOH}$ on $\mathrm{BiVO}_{4}$ will require further investigation.
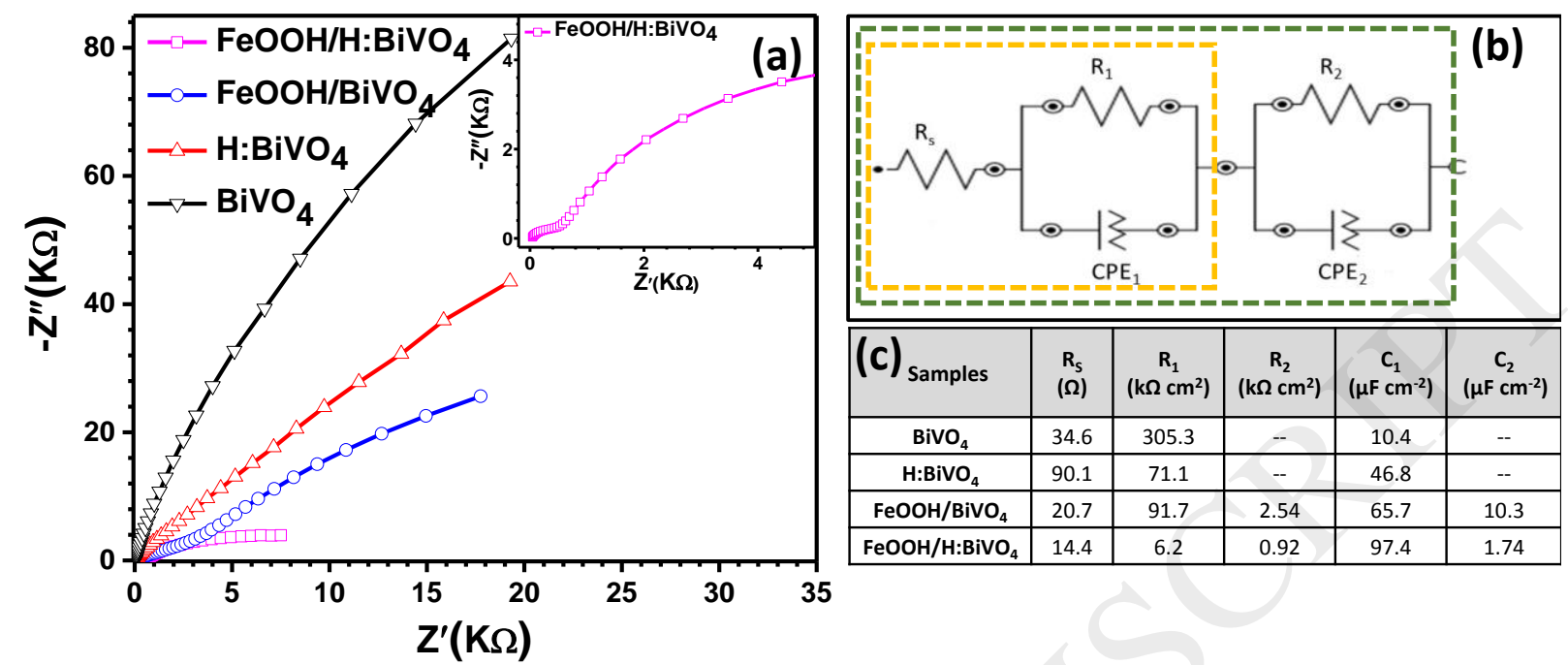

Figure 6: (a) EIS spectra (shown in form of Nyquist plots) for pristine $\mathrm{BiVO}_{4}, \mathrm{H}: \mathrm{BiVO}_{4}$, $\mathrm{FeOOH} / \mathrm{BiVO}_{4}$ and $\mathrm{FeOOH} / \mathrm{H}: \mathrm{BiVO}_{4}$ photoanodes recorded at $1.23 \mathrm{~V}_{\mathrm{RHE}}$ under $1 \mathrm{Sun}$ simulated irradiation (AC frequency range: $10^{5}-0.1 \mathrm{~Hz}, \mathrm{AC}$ amplitude $10 \mathrm{mV}$ ). (b) The equivalent circuits used to fit EIS data for electrodes without $\mathrm{FeOOH}$ (enclosed in the orange dashed box) and for electrodes with $\mathrm{FeOOH}$ (enclosed in the green dashed box). (c) Values of relevant parameters extracted from fitting of EIS data. $\mathrm{C}_{1}$ and $\mathrm{C}_{2}$ indicate the effective capacitances extracted from the correspondent constant phase elements $\mathrm{CPE}_{1}$ and $\mathrm{CPE}_{2}$.

\section{Conclusion}

Hydrogen treated $\mathrm{BiVO}_{4}$ thin films coupled with $\beta$-FeOOH overlayers exhibit superior PEC water splitting performance as compared to bare $\mathrm{BiVO}_{4}$ samples. The best performing $\mathrm{FeOOH} / \mathrm{H}: \mathrm{BiVO}_{4}$ electrode yields a remarkable photocurrent of $2.16 \mathrm{~mA} \mathrm{~cm}{ }^{-2}$ at $1.23 \mathrm{~V}_{\mathrm{RHE}}$. Moreover, the OER onset potential is as cathodic as $-0.11 \mathrm{~V}_{\mathrm{RHE}}$, just $40 \mathrm{mV}$ higher than the flat band potential. Additionally, the $\mathrm{FeOOH} / \mathrm{H}: \mathrm{BiVO}_{4}$ electrode showed no appreciable deterioration over $1 \mathrm{~h}$ of chronoamperometry at $1.23 \mathrm{~V}_{\text {RHE. }}$ The enhanced photocurrent upon the dual modification is originated by reduced bulk recombination thanks to more efficient charge transport, as confirmed by impedance spectroscopy characterization. The cathodic shift of the OER onset potential is partly attributed to the lowering of the flat band potential, partly to reduced surface recombination or enhanced OER rate. Conclusively, it can be said that $\mathrm{FeOOH} / \mathrm{H}: \mathrm{BiVO}_{4}$ allows higher efficiency for water splitting at low bias voltage than bare 
$\mathrm{BiVO}_{4}$ and such combination is promising for future research on heterojunction based on this semiconductor.

\section{Author Information}

Corresponding Authors e-mail: aadshp1982@gmail.com (A.P.S.), brmehta@physics.iitd.ac.in (B.R.M.) Tel: +91-11-26591333, Fax: +91-11-26581114

\section{Notes}

The authors declare no competing financial interest.

\section{Acknowledgements}

We gratefully acknowledge the financial support provided by the Department of Science and Technology, New Delhi India under the New Indigo and DST-UKERI program. A.P.S. is grateful to Department of Science \& Technology, New Delhi, India for financial support in terms of INSPIRE Faculty award No. IFA12-PH-16. Further we thank Formas (project number 245-2014-1478) for financial support. We are gratefully acknowledge the Nano Research Facility, IIT Delhi for Research facilities support.

\section{References}

[1]. M. Gratzel, Nature 414 (2001) 338-344.

[2]. T. Jafari, E. Moharreri, A. S. Amin, R. Miao, W. Song, S.L. Suib, Molecules 21 (2016) 900.

[3]. J.A. Seabold, K.S. Choi, J. Am. Chem. Soc. 134 (2012) 2186-2192.

[4]. A.P. Singh, N. Kodan, A. Dey, S. Krishnamurthy, B.R. Mehta, Int. J. Hydrogen Energy 40 (2015) 4311-4319.

[5]. A. Kudo, K. Omori, H. Kato, J. Am. Chem. Soc. 121 (1999) 11459-11467.

[6]. D.K. Zhong, S. Choi, D.R. Gamelin, J. Am. Chem. Soc. 133 (2011) 18370-18377.

[7]. M.S. Prévot, K. Sivula, J. Phys. Chem. C 117 (2013) 17879-17893. 
[8]. Y. Pihosh, I. Turkevych, K. Mawatari, J. Uemura, Y. Kazoe, S. Kosar, K. Makita, T. Sugaya, T. Matsui, D. Fujita, M. Tosa, M. Kondo, T. Kitamori, Sci. Rep., 5 (2015) 11141.

[9]. T. W. Kim, K.S. Choi, Science 343 (2014) 990-994.

[10]. K. R. Tolod, S. Hernández, N. Russo, Catalysts 7 (2017), 13.

[11]. Y. Park, K. J. McDonald, K.S. Choi, Chem. Soc. Rev. 42 (2013) 2321-2337.

[12]. J.K. Cooper, S. Gul, F.M. Toma, L. Chen, P.-A. Glans, J. Guo, J.W. Ager, J. Yano, I.D. Sharp, Chem. Mater. 26 (2014) 5365-5373.

[13]. F. F. Abdi, Roel van de Krol, J. Phys. Chem. C 116 (2012) 9398-9404.

[14]. W.J. Yin, S.-H. Wei, M. M. Al-Jassim, J.Turner, Y. Yan, Physical Review B 83 (2011) 155102.

[15]. W. Yao, H. Iwai, J. Ye, Dalton Trans. 11 (2008) 1426-1430.

[16]. Y. Park, D. Kang, K.S. Choi, Phys.Chem.Chem.Phys. 16 (2014) 1238-1246.

[17]. J. A. Seabold, K.Zhu, N. R. Neale, Phys.Chem.Chem.Phys. 16 (2014) 1121-1131.

[18]. H. Ye, H.S. Park, A.J. Bard, J. Phys. Chem. C 115 (2011) 12464-12470.

[19]. J. Yu, A. Kudo, Adv. Funct. Mater. 16 (2006) 2163-2169.

[20]. Z. Jiang, Y. Liu, T. Jing, B. Huang, X. Zhang, X. Qin, Y. Dai, M.H. Whangbo, J. Phys. Chem. C 120 (2016) 2058-2063.

[21]. J. Gan, X. Lu, B.B. Rajeeva, R.Menz, Y. Tong, Y. Zheng, ChemElectroChem 2 (2015) $1385-1395$.

[22]. J. K. Cooper, S. B. Scott, Y. Ling, J. Yang, S. Hao, Y.Li, F.M. Toma, M. Stutzmann, K. V. Lakshmi, I. D. Sharp, Chem. Mater. 28 (2016) 5761-5771.

[23]. S. K. Pilli, T.G. Deutsch, T.E. Furtak, J.A. Turner, L.D. Browna, A.M. Herring, Phys. Chem. Chem. Phys. 14 (2012) 7032-7039.

[24]. W.D. Chemelewski, H.C. Lee, J.-F. Lin, A. J. Bard, C.B. Mullins, J. Am. Chem. Soc. 136 (2014) 2843-2850.

[25]. T. W. Kim, K.S. Choi, Science 343 (2014) 990-994.

[26]. L. Trotochaud, S. L. Young, J. K. Ranney, S. W. Boettcher, J. Am. Chem. Soc. 136 (2014) 6744-6753. 
[27]. J. Huang, Y. Ding, X. Luo, Y. Feng, J. Catal. 333 (2016) 200-206.

[28]. J. A. Seabold, K. S. Choi, J. Am. Chem. Soc. 134 (2012) 2186-2192.

[29]. K. J. McDonald, K.-S. Choi, Energy Environ. Sci. 5 (2012) 8553- 8557.

[30]. X. Zhang, J. Ge, B. Lei, Y. Xue and Y. Du, CrystEngComm 17 (2015) 4064-4069.

[31]. M. Mehta, N. Kodan, S. Kumar, A. Kaushal, L. Mayrhofer, M.Walter, M.Moseler, A. Dey, S. Krishnamurthy, S. Basu and A. P. Singh, J. Mater. Chem. A 4 (2016) 26702681.

[32]. N. Bhandary, A. P. Singh, P. P. Ingole and S. Basu, RSC Adv. 6 (2016) 35239-35247.

[33]. R. Saito, Y. Miseki, K. Sayama, Chem. Commun. 48 (2012) 3833-3835.

[34]. K. Gelderman, L. Lee, S.W. Donne, J. Chem. Educ. 84 (2007) 685-688.

[35]. R.L. Frost, D.A. Henry, M.L. Weier, W.N. Martens, J. Raman Spectrosc. 37 (2006) $722-732$.

[36]. L. Bellot-Gurlet, D. Neff, S. Réguer, J. Monnier, M. Saheb, P. Dillmann, J. Nano Res. 8 (2009) 147-156.

[37]. S.M. Ho-Kimura, S.J.A. Moniz, A.D. Handoko, J. Tang, J. Mater. Chem. A 2 (2014) 3948-3953.

[38]. M. Chhetri, S. Dey, C. N. R. Rao, ACS Energy Lett. 2 (2017), 1062-1069.

[39]. S. Sarkar, N.S. Das, K.K. Chattopadhyay, Solid State Sci. 33 (2014) 58-66.

[40]. G. Silversmit, D. Depla, H. Poelman, G.B. Marin, R.D. Gryse, J. Electron. Spectrosc. Relat. Phenom., 135 (2004) 167-175.

[41]. B. Bharti, S. Kumar, H.-N. Lee, R. Kumar, Sci. Rep. 6 (2016) 32355.

[42]. M.C. Tsai, T.T. Nguyen, N. G. Akalework, C.J. Pan, J. Rick, Y.F. Liao, W.N. Su, B.J. Hwang, ACS Catal. 6 (2016) 6551-6559.

[43]. J.H. Kim, Y.J. Jang, J.H. Kim, J.W. Jang, S.H. Choi, J.S. Lee, Nanoscale 7 (2015) 19144-19151.

[44]. A. Mettenbörger, T. Singh, A. P. Singh, T.T. Järvi, M. Moseler, M. Valldor, S. Mathur., Int J. of Hydrogen Energy 39 (2014) 4828-4835.

[45]. N.S. McIntyre, D.G. Zetaruk, Anal. Chem. 49 (1977) 1521-1529.

[46]. D. Welsh, P.M.A. Sherwood, Phys. Rev. B 40 (1989) 6386 -6392. 
[47]. J. Moir, N. Soheilnia, K. Liao, P. O’Brien, Y. Tian, K.S. Burch, G.A. Ozin, ChemSusChem 8 (2015) 1557-1567.

[48]. A.P. Singh, N. Kodan, B.R. Mehta, A. Held, L. Mayrhofer, M. Moseler, ACS Catalysis 6 (2016) 5311-5318.

[49]. X. Yang, A. Wolcott, G. Wang, A. Sobo, R.C. Fitzmorris, F. Qian, J.Z. Zhang, Y. Li, Nano Lett. 9 (2009) 2331-2336.

[50]. M. Valant, D. Suvorov, J. Am. Ceram. Soc. 83 (2000) 2721-2729.

[51]. B. Iandolo, H. Zhang, B. Wickman, I. Zorić, G. Conibeer, A. Hellman, RSC Adv. 5 (2015) 61021-61030.

[52]. W. Li, D. He, S.W. Sheehan, Y. He, J. E. Thorne, X.Yao, G.W. Brudvig, D. Wang, Energy Environ. Sci. 9 (2016) 1794-1802. 